\title{
HUBUNGAN SENAM HAMIL DENGAN DURASI TIDUR IBU HAMIL TRIMESTER III DI POLI KLINIK KEBIDANAN PUSKESMAS TIBAN BARU TAHUN 2020
}

\author{
DETI HARTATI
}

\author{
Program Studi Ilmu Keperawatan \\ STIKes Awal Bros Batam \\ Email : detibatam1984@gmail.com
}

\begin{abstract}
When pregnancy enters the third trimester, physical and psychological changes will occur. Physical changes in the third trimester of pregnancy such as increased frequency of urination, enlarged uterus, back pain and fetal movement and psychological changes that occur during pregnancy include anxiety, fear and depression. This condition causes sleep disorders in pregnant women. The preliminary study conducted by researchers at the midwifery clinic of Puskesmas Tiban Baru amounted to 30 people. After being interviewed, 17 of them were pregnant women in their third trimester who had trouble sleeping at night. Management to overcome this difficulty sleeping includes non-pharmacological pregnancy exercises. This study aims to determine the relationship between pregnancy exercise with. This research method used cross sectional. This research instrument used an instrument, a sample of 30 pregnant people. The results of this study were that more than $67 \%$ of routine pregnancy exercise was performed and $77 \%$ good sleep duration, in this case the results of the Chi-square test conducted had a significant relationship between exercise. pregnant with sleep duration. With a significant value of $p<0.05$, that is $=0.002$. From the results of the study it can be concluded that there is a significant relationship between pregnancy exercise and sleep duration, in this case research suggests that for further research the factors that cause sleep duration are reduced in pregnant women.
\end{abstract}

Keywords: Pregnancy exercise, sleep duration, pregnant women

\section{PENDAHULUAN}

Prevalensi gangguan tidur pada ibu hamil di Kepri pada tahun 2010 cukup tinggi yaitu sebesar 23\% (Puspita, 2014). Fenomena yang terjadi Puskesmas Tiban Baru menempati peringkat terakhir yaitu sebesar $68.2 \%$ angka ini terpaut jauh dari target SPM dalam pelayanan komplikasi kebidanan. Hal ini dapat dilihat rendahnya kaderisasi pemeriksaan ibu hamil di puskesmas (Dinas Kesehatan Batam 2015).

Dampak gangguan pola tidur jika terjadi secara berkepanjangan selama kehamilan maka dikhawatirkan bayi yang akan dilahirkan memiliki berat badan lahir rendah (BBLR), perkembangan sarafnya tidak seimbang, lahir prematur dan melemahnya sistem kekebalan tubuh bayi. Selain itu juga gangguan tidur menimbulkan depresi dan stres yang berpengaruh pada janin yang dikandungnya. Stres ringan menyebabkan janin mengalami peningkatan denyut jantung, tetapi stres yang berat dan lama akan membuat janin menjadi menjadi lebih hiperaktif (Okun, Schetter \& Glynn, 2015). Menurut Wangel, et al.(2015) gangguan pola tidur pada ibu hamil juga dapat meningkatkan persalinan lama yang berujung pada persalinan secara operasi sesar.

Olahraga di pagi hari seperti jalan-jalan pagi hari atau olahraga yang bersifat kelompok seperti senam hamil bisa dilakukan untuk memperlancar sirkulasi darah ibu dan meningkatkan relaksasi pada 
ibu hamil bisa dilakukan secera rutin (Roosytasari, 2014). Wanita hamil dianjurkan melakukan olahraga ringan seperti senam hamil agar ibu dan janin lebih sehat dan berkurangnya masalah-masalah yang timbul pada kehamilannnya. Dalam gerakan senam hamil terkandung efek relaksasi yang bermanfaat menstabilkan kecemasan dan mengurangi rasa takut dengan cara relaksasi fisik dan mental, serta mendapatkan informasi yang mempersiapkda mereka untuk mengalami apa yang akan terjadi selama persalinan dan kelar (Brayshaw, 2016).

Tentu hal ini menjadi masalah yang $h$ di tuntaskan dalam hal ini per memberikan edukasi kepada ibu $h$ dengan mengikuti senam ibu hamil ? membantu meningkatkan kualitas tidur : terganggu. Seperti halnya teori: dijelaskan bahwasanya Wanita $h$ dianjurkan melakukan olahraga riı selama hamil agar kandungannya sehat serta 2 Pendidikan mengurangi masalah-masalah yang biasa timbul saat kehamilan seperti spasme, varises, hipertensi, oedema, nyeri pinggang,

HASIL DAN PEMBAHASAN

Tabel 4.1

Distribusi Responden Berdasarkan jenis kelamin, usia, pendidikan, Ibu Hamil Trimester III Di Poli Klinik Kebidanan Puskesmas Tiban Baru Tahun 2020.

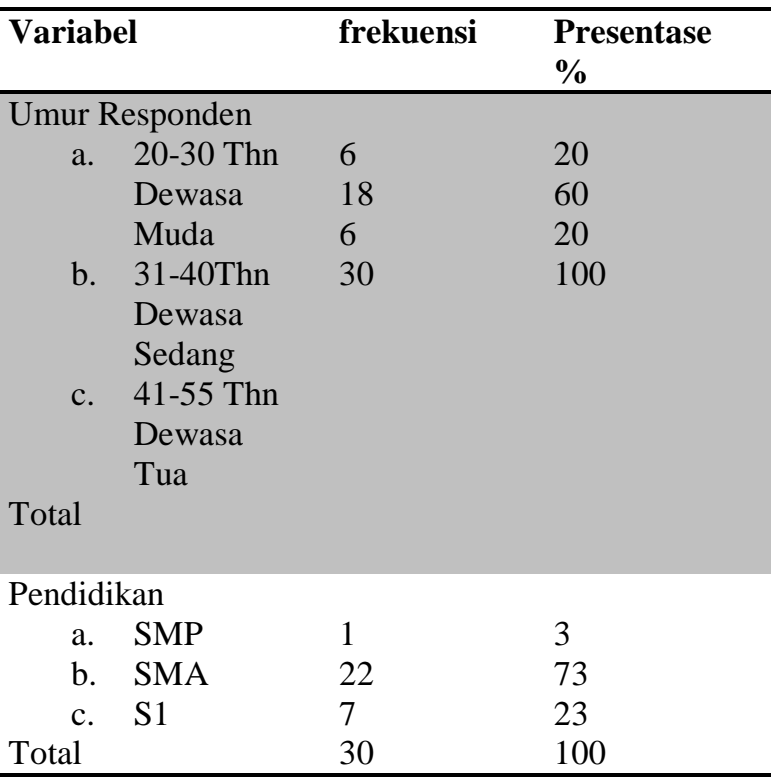
sesak napas, susah tidur dan masalah lainnya.

Berdasarkan hal diatas, maka dari itu peneliti tertarik untuk melakukan penelitian mengenai "hubungan Senam Hamil dengan durasi Tidur Ibu Hamil Trimester III Di Poli Klinik Kebidanan Puskesmas Tiban Baru Tahun 2019"

\section{METODOLOGI PENELITIAN}

Penelitian ini merupakan penelitian deskriptif kuantitatif dengan desain Cross Secctional Study yaitu suatu rancangan penelitian yang mempelajari dinamika korelasi dan asosiasi antara variable indenpenden senam hamil dengan variable dependen durasi tidur ibu hamil dan menggunakan uji Chi Square
Tabel 4.2

Distribusi Frekuensi Senam Hamil Trimester III Di Poli Klinik Kebidanan Puskesmas Tiban Baru Tahun 2020

\begin{tabular}{ccc}
\hline $\begin{array}{c}\text { Senam } \\
\text { Hamil }\end{array}$ & Frekuensi & $\begin{array}{c}\text { Persentase } \\
(\boldsymbol{\%})\end{array}$ \\
\hline Rutin & 20 & 67.0 \\
Tidak & 10 & 33.0 \\
rutin & & \\
Total & 30 & 100 \\
\hline
\end{tabular}

Dari Tabel 4.2 senam hamil rutin di lakukan yaitu $67 \%$

Tabel 4.3

Distribusi Frekuensi Durasi Tidur Ibu Hamil Trimester III Di Poli Klinik Kebidanan Puskesmas Tiban Baru Tahun 2019

\begin{tabular}{ccc}
\hline $\begin{array}{c}\text { Durasi } \\
\text { tidur }\end{array}$ & Frekuensi & $\begin{array}{c}\text { Persentase } \\
(\boldsymbol{\%})\end{array}$ \\
\hline Baik & 23 & 77.0 \\
$\begin{array}{c}\text { Tidak } \\
\text { baik }\end{array}$ & 7 & 23.0 \\
Total & 30 & $100 \%$ \\
\hline
\end{tabular}


Dari Tabel 4.3. durasi tidur pada ibu hamil baik yaitu $77 \%$

Tabel 4.6

Hubungan Senam Hamil dengan Durasi

Tidur Ibu Hamil Trimester III Di Poli

Klinik Kebidanan Puskesmas Tiban Baru Tahun 2020

\begin{tabular}{|c|c|c|c|c|c|c|c|}
\hline \multirow{3}{*}{$\begin{array}{c}\text { Senam } \\
\text { hamil }\end{array}$} & \multicolumn{4}{|c|}{ Durasi tidur } & \multicolumn{2}{|c|}{ Total } & \multirow[t]{3}{*}{$\rho$} \\
\hline & \multicolumn{2}{|c|}{ Baik } & \multicolumn{2}{|c|}{$\begin{array}{c}\text { Tidak } \\
\text { baik }\end{array}$} & & & \\
\hline & $\mathbf{n}$ & $\%$ & $\mathrm{n}$ & $\%$ & $\mathrm{n}$ & $\%$ & \\
\hline Rutin & 18 & 60 & 5 & 17 & 23 & 77 & \\
\hline $\begin{array}{l}\text { Tidak } \\
\text { rutin }\end{array}$ & 2 & 7 & 5 & 17 & 7 & 23 & 0.002 \\
\hline Total & 20 & 66 & 10 & 34 & 30 & 100 & \\
\hline
\end{tabular}

hasil Uji menggunakan bantuan aplikasi komputer yaitu SPSS dilakukan uji ChiSquare Test dan diperoleh nilai signifikan $0,002 \quad(\rho=<0,005)$ Yang berarti ada

Hubungan Senam Hamil dengan Durasi Tidur Ibu Hamil Trimester III Di Poli Klinik Kebidanan Puskesmas Tiban Baru Tahun 2019

HASIL PENELITIAN

Hubungan Senam Hamil dengan Durasi Tidur Ibu Hamil Trimester III Di Poli Klinik Kebidanan Puskesmas Tiban Baru Tahun 2019

hasil Uji menggunakan bantuan aplikasi komputer yaitu SPSS dilakukan uji ChiSquare Test dan diperoleh nilai signifikan $0,002 \quad(\rho=<0,005)$ Yang berarti ada Hubungan Senam Hamil dengan Durasi Tidur Ibu Hamil Trimester III Di Poli Klinik Kebidanan Puskesmas Tiban Baru Tahun 2019

hasil Menurut Bustami, dkk. (2016) mengatakan bahwa terdapat hubungan antara kualitas tidur dengan preeklamsia dimana uji analisis Chi-Square didapatkan nilai $\mathrm{p}$ sebesar 0,001 sehingga Ha diterima ( $\mathrm{p}$ $<0,05)$. Hal ini di karenakan pada saat stressor datang disebabkan oleh gangguan tidur, maka hormone norepinefrin dan epinefrin disekresikan oleh kelenjar medulla adrenal dan efek dari perangsangannya yaitu langsung pada organ-organ spesifik seperti pembuluh darah dan jantung. Kedua hormon tersebut langsung membuat pembuluh darah setiap jaringan akan mengalami vasokontriksi sehingga membuat tahanan perifer meningkat yang akhirnya dapat meningkatkan tekanan darah dan sulit untuk tidur (Delaune \& Ladner, 2011)

Dalam hal ini peneliti berasumsi ada hubungan yang signifikan antara senam hamil dengan durasi tidur pada ibu hamil dalam hal ini dengan adanya penelitian ini menjadi acuan untuk bagi tenaga kesehatan dalam memberikan edukasi senam hamil yag mengalami gangguan tidur. Namun dalam hal ini ibu hamil yang mengikuti senam rutin juga masih mengalami masalah tidur tentu hal ini mungkin di pengaruhi oleh beberapa factor lain yang menjadi masalah tidur . pada ibu hamil Beberapa hal yang dapat menurunkan kualitas tidur ibu hamil dapat diatasi dengan pemberian senam hamil oleh fisioterpis seperti kecemasan ibu hamil, sesak napas dan nyeri pinggang. Namun, frekuensi berkemih yang meningkat seiring dengan bertambahnya usia kehamilan merupakan keadaan fisiologis bagi ibu hamil yang tidak dapat diturunkan dengan melakukan senam hamil. Secara fisiologis, peningkatan frekuensi berkemih ibu disebabkan oleh tekanan uterus kearah bawah karena turunnya bagian bawah janin sehingga kandung kemih tertekan dan kapasitas kandung kemih berkurang. Dengan berkurangnnya kapasitas kandung kemih maka kandung kemih akan lebih cepat terasa penuh sehingga frekuensi berkemih ibu akan meningkat.

\section{KESIMPULAN}

Berdasarkan hasil penelitian yang dilakukan terhadap 30 responden Hubungan Senam Hamil dengan Durasi Tidur Ibu Hamil Trimester III Di Poli Klinik Kebidanan Puskesmas Tiban Baru Tahun 2020 menyimpulkan sebagai berikut:

1. Lebih dari sebagian $67.0 \%$ senam ibu hamil rutin

2. Lebih dari sebagian $77 \%$ durasi tidur ibu hamil baik 
3. Adanya hubungan antara senam hamil dengan durasi tidur dengan uji ChiSquare Test dan diperoleh nilai signifikan $0,002(\rho=<0,005$

\section{DAFTAR PUSTAKA}

Ashari, A., Pongsibidang, G. S., \& Mikhrunnisai, A. (2019). Pengaruh Senam Prenatal Yoga terhadap Penurunan Kecemasan Ibu Hamil Trimester III. Media Kesehatan Masyarakat Indonesia, 15(1), 55.

https://doi.org/10.30597/mkmi.v15i1.5554

Andriyani, F.D. (2014). Physical Activity

Guidelines for Children. Jurnal Pendidikan

Jasmani Indonesia, 10, 61-67.

Aprianti, I. (2012). Hubungan antara Percived

Social Support dan Psychological Well-Being pada Mahasiswa Perantau Tahun Pertama di

Universitas Indonesia. Skripsi, tidak diterbitkan,

Universitas Indonesia, Jakarta.

Arikunto, S. (2006) Hubungan senam hamil dengan kualitas tidur ibu hamil trimester iii di klinik pera kecamatan medan tuntungan tahun 2018.

Atkinson, G., \& Davenne, D. (2007). Relationships Between Sleep, Physical Activity and Human Health. Physiology \& Behavior, 90, 229-235. Badan Penelitian dan Pengembangan Kesehatan. (2013).

Arikunto, S. (2016) Hubungan Faktor

Lingkungan Dan Perilaku Dengan Kejadian

Demam Berdarah Dengue (Dbd) Di Wilayah

Kelurahan Perumnas Way Halim Kota

Bandar Lampung, 2(April), 608-614.

https://doi.org/10.13243/j.cnki.slxb.2013.05.0 13

Atmadja W., B. (2010). Fisiologi Tidur. Jurnal

Kedokteran Maranatha, 1(2), 36- 39.

Retrieved from

httssssp://majour.maranatha.edu/index.php/ju rnalkedokteran/article/view/25/pdf.

Aliyah, J. (2016). Pengaruh Pemberian Senam

Hamil Terhadap Tingkat Kecemasan dan Kualitas Tidur Ibu Hamil di Puskesmas Samata Kabupaten Gowa. Program Studi
Fisioterapi Fakultas Kedokteran Universitas Hasanuddin. Makassar.

Brick, Lynne. 2001. Bugar dengan Senam Aerobik. Jakarta : PT. Raja Grafindo Persada

Bobak, I. Lowdermilk, D. Jensen, M. (2005). Buku ajar keperawatan maternitas. (4thed). Alih bahasa: Wijayarini, M. Jakarta: EGC.

Hegard, H. K. (2010). Experience of physical activity during pregnancy in Danish nulliparous women with a physically active life before pregnancy, a qualitative study. BMC Pregnancy and Childbirth, 10 (33)

Jumhati, S., \& Kurniawan, S. S. (2019). ANALISIS FAKTOR-FAKTOR YANG MEMPENGARUHI TREND PENURUNAN PELAKSANAAN SENAM IBU HAMIL DI KABUPATEN. 11(1), 27-36.

Marwiyah, N., \& Sufi, F. (2018). Pengaruh Senam Hamil Terhadap Kualitas Tidur Ibu Hamil Trimester II dan III di Kelurahan Margaluyu Wilayah Kerja Puskesmas Kasemen. Faletehan Health Journal, 5(3), 123-128. https://doi.org/10.33746/fhj.v5i3.34 Mandriwati. (2008). Asuhan Kebidanan Ibu Hamil. Jakarta: EGC

Manuaba, I. B. G. (2010). Ilmu Kebidanan, penyakit Kandungan dan KB untuk Pendidikan Bidan Edisi 2. Jakarta: EGC

Maretdhidta, C. A. (2013). Pengaruh Back Massage Durasi 20 Menit Dan 40 Menit Untuk Meningkatkan Kualitas Tidur. Program Studi Diploma IV Fisioterapi Fakultas Ilmu Kesehatan Universitas Muhammadiyah Surakarta.

National Sleep Foundation. (2007). Excessive sleepiness and sleep. 
http://www.sleepfoundation.org/article/sleeprelated-problems/excessivesleepiness-andsleep. diakses tanggal 11 maret 2016 pukul 13.46

Perry. Potter. (2005). Buku Ajar Fundamental Keperawatan Konsep, Proses, dan Praktik. Volume 1. Edisi 4. Jakarta : EGC.

Riza Berdian Tamza1, Dr. dr. Suhartono, M.Kes2, dr. Dharminto, M. K. (2013). Jurnal Kesehatan Masyarakat 2013,. Hubungan Faktor Lingkungan Dan Perilaku Dengan Kejadian Demam Berdarah Dengue (Dbd) Di Wilayah Kelurahan Perumnas Way Halim Kota Bandar Lampung, 2(April), 608-614. https://doi.org/10.13243/j.cnki.slxb.2013.05.0 13

Rahma, F. N. (2014). Hubungan Senam Yoga Terhadap Kualitas Peningkatan Tidur pada Ibu Hamil Trimester III. Program Studi S1 Fisioterapi Fakultas Ilmu Kesehatan Universitas Muhammadiyah Surakarta.

Sinaga, L. V. (2018). Hubungan senam hamil dengan kualitas tidur ibu hamil

SAmbardini, R.L. (2009). Pendidikan Jasmani dan Prestasi Akademik: Tinjauan Neuorosains. Jurnal Pendidikan Jasmani Indonesia, 6, 1-1

Santiago, J. R. Nolledo, M. S. Kinzier, W. and Santiago, T. V. (2001). Sleep and Disorders in Pregnancy. Annals of Internal Medicine, 134(5):396-408

Sharma, S. and Franco, R. (2004). Sleep and its Disorders in Pregnancy. Wisconsin Medical Journal, 103(5)

Sinclair, Costance. 2009. Kondisi Ginekologi dan Pertimbangan Kehamilan serta Kontrasepsi. Buku Saku Kebidanan. Jakarta: ECG.
Wahyuni. Ni'mah, L. (2013). Manfaat Senam Hamil Untuk Meningkatkan Durasi Tidur Ibu Hamil. KEMAS 8 (2) 145-152. Surakarta Yuliasari. (2010). Hubungan Pengetahuan dan Sikap Dengan Pelaksanaan Senam Hamil (Studi Pada Ibu Hamil Trimester II dan III) Di Puskesmas Ciputat Tangerang Selatan.

Wahyuni. Ni'mah, L. (2013). Manfaat Senam Hamil Untuk Meningkatkan Durasi Tidur Ibu Hamil. KEMAS 8 (2) 145-152. Surakarta 